\title{
NUEVOS DATOS SOBRE EL ORIGEN DEL LAGO DE LA BAÑA (SIERRA DE LA CABRERA, NO DE ESPAÑA) A PARTIR DEL ANÁLISIS GEOMORFOLÓGICO Y SEDIMENTOLÓGICO
}

\author{
J. Santos González \\ J.M. Redondo Vega \\ R.B. González Gutiérrez \\ A. Gómez Villar \\ Departamento de Geografía y Geología. Universidad de León \\ jsango@unileon.es; blanca.gonzalez@unileon.es; jmredv@unileon.es; agomv@unileon.es
}

\section{RESUMEN}

El Lago de la Baña se localiza en la cabecera del Valle del Lago, en un entorno con numerosos restos glaciares que indican una ocupación por el hielo relativamente extensa. Debido a ello, este lago se consideró de origen glaciar ya que se identificó como morrena la acumulación de grandes bloques que lo obtura. Sin embargo, el análisis sedimentológico y de fábrica de esos sedimentos y su comparación con otros depósitos próximos, confirman que en realidad el responsable del cierre es un gran deslizamiento de rocas. La composición interna del depósito lo hace muy vulnerable a las voladuras de las canteras de pizarra cercanas.

Palabras clave: Geomorfología; Sierra de la Cabrera; Análisis de fábrica; Deslizamientos; Glaciarismo.

\section{ABSTRACT}

New data about the La Baña Lake origin (Cabrera Range, NW Spain) using geomorphological and sedimentological analysis. La Baña lake is located in the upper part of a glacial valley. Due to glacial morphology in the surroundings, the lake-dammed deposit,

Fecha de recepción: noviembre 2012.

Fecha de aceptación: noviembre 2013. 
composed by big slate boulders, was considered a moraine. Macrofabric and sedimentology analysis of lake-dammed deposit and the comparison with other periglacial and glacial deposits, demonstrate the landslide origin of the deposit. Because of the deposit composition, it is vulnerable to explosions in nearby quarries.

Key words: Geomorphology; Cabrera Range; fabric analysis; landslides; glacial geomorphology;

\section{INTRODUCCIÓN}

El Lago de la Baña se localiza en el Valle del Lago, en la Sierra de la Cabrera, al SO de la provincia de León, en el límite con las provincias de Zamora y Orense, a 1400 m de altitud. En su entorno hay rasgos de morfología glaciar de gran valor patrimonial, con circos muy bien desarrollados, así como umbrales, pequeñas cubetas y depósitos glaciares que se extienden hasta las proximidades de la localidad de La Baña, a unos 1000 m de altitud.

El relieve y, en concreto, las dos masas de agua que dan personalidad al espacio, el Lago de la Baña (6,5 ha) y La Laguna (0,7 ha), son los elementos más singulares y la base para que todo el espacio se integrara en la Red de Espacios Naturales de la Junta de Castilla y León en el año 1992, cuando todo el entorno fue declarado Monumento Natural. Asimismo, forma parte del Lugar de Importancia Comunitaria (LIC) y la Zona de Especial Protección para las Aves (ZEPA) de la Sierra de la Cabrera. El Lago de la Baña aparece desde entonces en los inventarios que destacan el patrimonio geológico bien como Punto de Interés Geológico (Alonso Herrero y Gallego Valcarce, 1995), bien como Lugar de Interés Geológico (Fernández Martínez, et al., 2009).

La presencia de estas dos masas de agua en un contexto con rotundas formas glaciares, ha llevado a considerar el depósito de cierre de las mismas como una morrena, y así se recoge en la información que sobre el Monumento Natural se ofrece de manera oficial. Sin embargo, un detallado análisis de la estructura y la morfología del depósito que obtura el valle, junto con la comparación con otros cercanos, nos lleva a plantear un origen distinto para las mismas.

\section{II. ÁREA DE ESTUDIO}

El Lago de la Baña se ubica en la vertiente septentrional de la Sierra de la Cabrera, en el límite con la comarca zamorana de Sanabria, en el Valle del Lago. Este valle constituye la cabecera del río Cabrera, principal arteria de la comarca homónima; tiene una longitud de 6,7 km entre el área cimera que culmina a 2079 m en El Picón, la zona más baja, a 1200 m, donde comienza propiamente el río Cabrera.

Desde un punto de vista geológico, la zona forma parte del Macizo Ibérico, en el límite entre la Zona Asturoccidental-Leonesa y la Zona Centro-Ibérica, en el Dominio del Sinclinorio de Truchas (esta última sólo aparece en el extremo meridional del mencionado valle, es decir, en su parte más alta). Los materiales son del Paleozoico Inferior y destacan las siguientes formaciones orientadas de ONO a ESE (Pérez Estaún, et al., 1978; Barettino Fraile, 2002; Martínez Catalán et al., 2004) (Figura 1): 


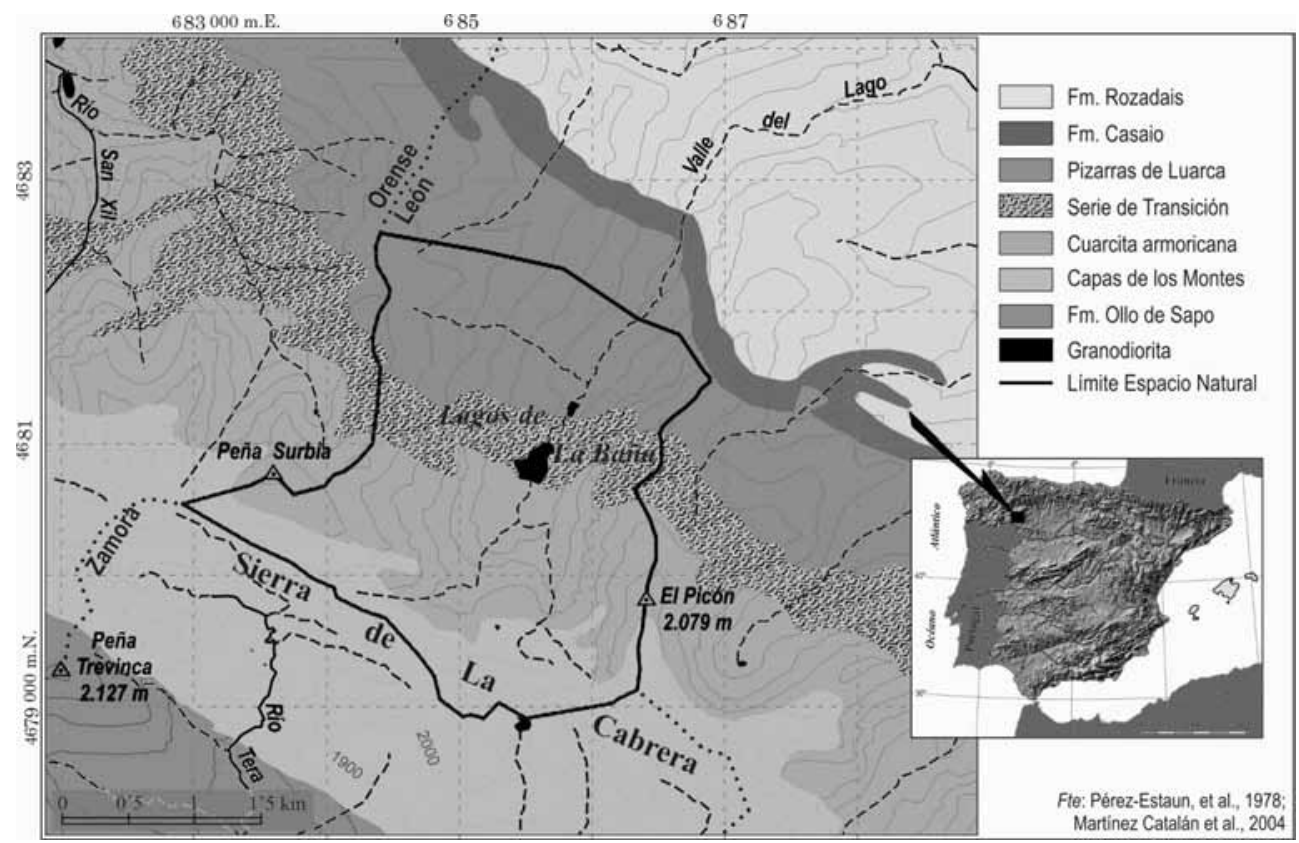

- Capas de los Montes: están integradas por unos $500 \mathrm{~m}$ de pizarras negras con intercalaciones de areniscas y cuarcitas, del Ordovícico Inferior, que se emplazan sobre los ortogneises granulares de la Fm. Ollo de Sapo, que se encuentran al SO del área de estudio. Las Capas de los Montes arman las zonas culminantes del Valle del Lago.

- Cuarcita armoricana: se trata de un extenso afloramiento de cuarcitas blancas, muy resistentes a la erosión y de gran trascendencia en el relieve, ya que forman los escarpes del circo glaciar, así como las cumbres de El Picón y Peña Surbia.

- Serie de Transición: se sitúa inmediatamente al N, en el entorno del Lago de la Baña, e integra un conjunto de 150-200 $\mathrm{m}$ de espesor en el que alternan pizarras, areniscas y cuarcitas, dominando a techo las pizarras.

- Pizarras de Luarca: constituyen un extenso afloramiento de entre 200 y $500 \mathrm{~m}$ de espesor de pizarras negras del Ordovícico Medio.

- Formación Casaio: integrada por una alternancia de pizarras gris oscuras con areniscas y cuarcitas, con un espesor total de unos 150 metros.

- Formación Rozadais: aparece situada en la parte más septentrional del Valle del Lago y es una banda de unos $400 \mathrm{~m}$ de pizarras gris-azuladas con algunos niveles de areniscas y cuarcitas, pertenecientes al Ordovícico Superior.

Las dos últimas formaciones se integraban dentro de la Formación Agüeira y, al igual que el miembro inferior de las Pizarras de Luarca, están siendo intensamente explotadas 
para la obtención de pizarras para techar, encontrándose la parte baja del Valle del Lago (unas 300 ha) ocupada casi totalmente por varias canteras de pizarra.

Todas estas rocas se encuentran fuertemente tectonizadas, con buzamientos subverticales, mediante pliegues asimétricos y vergentes que siguen la dirección mencionada, además de fallas y fracturas en esa dirección o en la transversal, que se atribuyen a la Orogenia Varisca. Una de las fracturas principales es a la que se ajusta todo el Valle del Lago.

Desde un punto de vista morfoestructural, toda la zona forma parte de la Sierra de Cabrera, que es un segmento del Zócalo Herciniano arrasado y levantado por la Orogenia Alpina a más de 2000 m (García Fernández, 2006: 53). Tal circunstancia se manifiesta en la conservación de extensos chanos culminantes en la divisoria meridional con la provincia de Zamora, donde las pizarras del Ordovícico Inferior y el gneis de la Formación Ollo de Sapo aparecen nivelados y enrasados.

En la evolución del relieve es muy relevante la diferencia de potencial morfogenético entre la vertiente norte de la Sierra de la Cabrera, que drena hacia la cuenca del Miño-Sil (ríos Cabrera, San Xil y afluentes) y la vertiente sur, que constituye la cabecera del río Tera, afluente del Duero. Esta diferencia, acentuada por las diferencias litológicas entre ambas zonas, se traduce en una asimetría morfológica muy evidente entre ambas vertientes, con valles muy escarpados y elevada pendiente longitudinal hacia el norte, y valles apenas incididos y con formas muy suaves hacia el sur.

El Valle del Lago se emplaza en un espacio con rotundas huellas de la acción glaciar. Hacia el S, en la cabecera del Tera, se instaló un extenso campo de hielo que emitió lenguas tanto hacia el Tera (Rodríguez Rodríguez et al., 2011b) como hacia el Bibey y el Xares (Rodríguez Guitián y Valcárcel Díaz, 1994), formando uno de los principales focos glaciares de la Península Ibérica. En esta zona la altitud de la línea de equilibro glaciar (ELA) se situó en torno a los 1520 m (Rodríguez Rodríguez et al., 2011a), similar a la que hubo en buena parte de la Cordillera Cantábrica (Santos-González et al., 2013a).

Hacia el N, hacia el Valle del Lago, la alimentación del campo de hielo debió ser menor, pero sin duda el glaciar que ocupó el valle estaba conectado con aquel. Por su parte, otras cabeceras próximas y con escasa alimentación desde la plataforma superior también generaron lenguas glaciares de cierta importancia (4-6 km), como los valles del Cuadro, Cadabal, Montrabea o Faeda (Schmidt, 1969). Con el retroceso glaciar, estas lenguas septentrionales debieron quedar progresivamente aisladas del campo de hielo, manteniéndose durante un tiempo hasta su total desaparición gracias a la favorable orientación de los circos.

Las huellas que los glaciares dejaron en el Valle del Lago son contundentes. En primer lugar destaca el amplio anfiteatro de la cabecera del valle y que no es sino un circo glaciar compuesto de algo más de $2 \mathrm{~km}$ de anchura, en el que aparecen varios pequeños rellanos y grandes escalones rocosos, adaptados a la estructura geológica y a la mayor o menor resistencia de los materiales (Figura 2). En la parte inferior del valle, dos morrenas laterales, ya casi totalmente destruidas por las canteras de pizarra, flanqueaban las laderas del valle, revelando un espesor de hielo de unos $200 \mathrm{~m}$ a más de $5 \mathrm{~km}$ de la cabecera. Por otra parte, son visibles algunos umbrales pulidos, así como depósitos de till, generalmente cubiertos de vegetación. 
Figura 2

VISTA DEL LAGO DE LA BAÑA Y DEL GRAN CIRCO GLACIAR QUE LO ENMARCA. EN LA OTRA VERTIENTE (HACIA SANABRIA) SE DESARROLLÓ UN EXTENSO CAMPO DE HIELO, PARTE DEL CUAL, DESBORDABA SOBREALIMENTANDO ESTA CABECERA. EN LA COLA DEL LAGO (PARTE CENTRAL-IZQUIERDA DE LA IMAGEN) SE PUEDE APRECIAR UN CONO DE PIEDRAS DE FUERTE PENDIENTE Y OTRO CONO ALUVIAL, EN LA PARTE CENTRAL, CON UN GRADIENTE MUCHO MÁS SUAVE

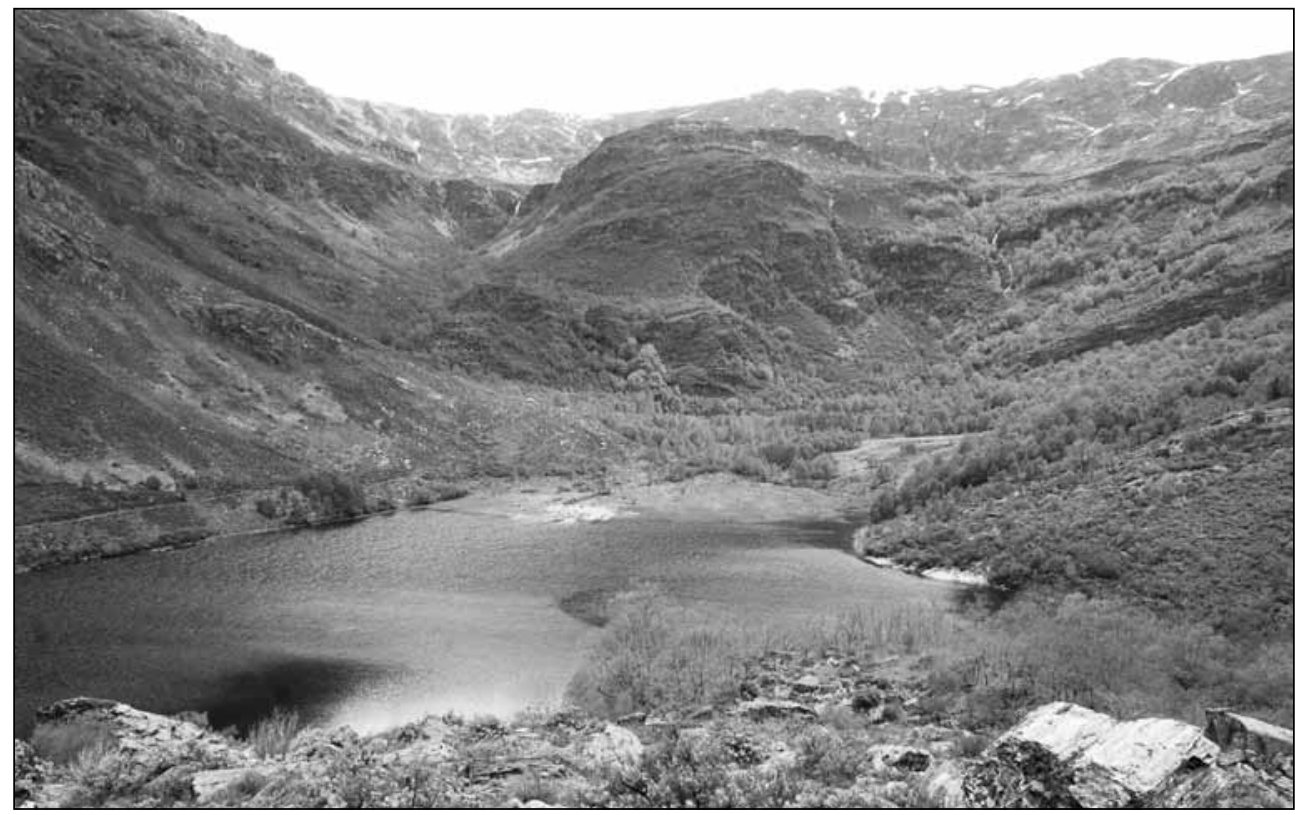

Tras la deglaciación, otros procesos modifican el perfil del valle, destacando un cono de piedras, de unas 3,5 ha, situado en la cabecera del valle, con elevada pendiente longitudinal y que incluye algunos bloques de gran tamaño. A este se superpone otro abanico de escasa pendiente y con cierta funcionalidad actual que se desarrolla a modo de delta en la cola del lago, formado en un momento incierto y que después discutiremos más ampliamente. Este abanico está progresivamente colmatando de sedimentos el Lago de la Baña. De hecho, entre ambos han debido reducir significativamente el tamaño del mismo desde su dimensión original, que probablemente fuera netamente superior a la actual.

\section{ANTECEDENTES}

Los estudios geomorfológicos sobre el entorno del Lago (o Lagos) de la Baña son muy escasos y, en general, se trata siempre de escuetas referencias dentro de trabajos de carácter más general. Debemos tener en cuenta que la comarca de La Cabrera ha sido tradicionalmente una de las zonas más inaccesibles del país, con unas comunicaciones deficientes. Así, aunque ya De Prado (1862) se refiere a la existencia del lago, la primera cita referida al glaciarismo de la zona es la de Vosseler (1931) que incluye un mapa general con la representación de una lengua glaciar que ocupó la cabecera del Valle del Lago. 
Carlé (1949: 704) considera que los lagos son de sobre-excavación glaciar, con el «agua acumulada detrás del cerrojo rocoso en cada uno de ellos». Unos años después, es Llopis Lladó (1957) el primero que representa gráficamente lo que él considera una morrena que cierra el Lago de la Baña, dentro de unas notas sobre las comarcas de Sanabria y Cabrera. Más detallada es la descripción de Schmidt (1969: 54), para quien el glaciar de La Baña alcanzó los $6 \mathrm{~km}$ de recorrido, dejando dos morrenas de retroceso, compuestas por grandes bloques de pizarra, que cierran ambas lagunas.

Posteriormente apenas hay estudios sobre la geomorfología de la zona. En la cartografía del Mapa Geológico Nacional, a escala 1:50.000, se representa gráficamente el depósito que cierra el lago y se le considera como de origen glaciar (Pérez Estaún et al., 1978). Por su parte, Cabero Diéguez (1980: 22) describe que las formas glaciares más rotundas en la zona de La Cabrera están en torno al Lago de la Baña, sin más precisión. Alonso Herrero y Gallego Valcárcel (1995) incluyen al «lago y morrena de La Baña» como uno de los Puntos de Interés Geológico de León.

No es hasta el presente siglo cuando se plantea, por primera vez, que el depósito de cierre es un gran deslizamiento, con las breves citas de Alonso Herrero (2004), dentro de una guía divulgativa del patrimonio geológico de la provincia de León y de Redondo Vega et al. (2004), en un proyecto de cartografía inédito. Igualmente, en el Inventario de Lugares de Interés Geológico de la provincia de León (Fernández Martínez et al., 2009) se vuelve a incidir en que el origen del lago y la laguna es un gran deslizamiento y no una morrena.

Sin embargo, en la información oficial de la Junta de Castilla y León referida al Monu-

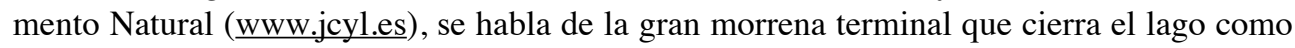
uno de los elementos más característicos de este espacio. Todo ello hacía necesaria la realización de análisis detallados de los sedimentos de la zona que ayudaran a esclarecer el origen de la gran acumulación de materiales que cierra las lagunas, lo cual constituye el principal objetivo de este estudio.

\section{METODOLOGÍA}

Para este trabajo se realizó en primer lugar un análisis de las formas de relieve a partir de la fotointerpretación. Además, la observación de la composición del depósito de cierre de los lagos, con grandes lajas y bloques de pizarra, nos llevó a realizar un análisis geomorfológico más profundo, incluyendo aspectos sedimentológicos.

Con objeto de comparar la estructura interna de varios depósitos, llevamos a cabo tres macrofábricas superficiales en la acumulación que represa el Lago de la Baña y La Laguna (dos en la margen izquierda y otra en la margen derecha), así como en un depósito de ladera cercano y en otro, presumiblemente glaciar, en la pista de acceso al Monumento Natural.

En cada caso se tomaron los datos de dimensión, orientación e inclinación del eje mayor, índice de desgaste y litología de 50 clastos, seleccionando preferentemente aquellos con una relación entre el eje mayor y el eje menor de al menos 1,5 , ya que se adaptan mejor a las direcciones de flujo de los agentes sedimentarios (Millar y Nelson, 2003).

La comparación de las características de la fábrica de estos depósitos, junto con las observaciones realizadas, ha servido para establecer una secuencia evolutiva relativa del Valle del Lago y el origen del Lago de la Baña y de La Laguna. 


\section{ANÁLISIS DE SEDIMENTOS EN EL ENTORNO DEL LAGO DE LA BAÑA}

Los estudios de macrofábrica se refieren al análisis de las propiedades visibles a simple vista de un sedimento y han sido utilizados frecuentemente como elemento de apoyo a las interpretaciones geomorfológicas (Evans y Benn, 2004). Si bien su uso en la Península Ibérica ha sido escaso (Redondo Vega et al., 2010; Santos González, 2013; Santos-González et al., 2015), acompañados del análisis del resto de propiedades de los sedimentos, pueden ser muy útiles para la correcta identificación del origen de los depósitos.

En nuestro caso hemos analizado tres tipos de depósitos diferentes situados próximos al Lago de La Baña, describiendo la situación, extensión, morfología y composición interna de los mismos. Todo ello nos ha servido para discriminar su origen y poder realizar una adecuada interpretación geomorfológica del lugar.

\section{V.1. Depósito $n^{0} 1$}

Se sitúa al pie de un escarpe de la Serie de Transición (Figura 3), en la margen derecha del Lago de la Baña, a 1435 m de altitud. Tiene una extensión superficial visible muy reducida $(0,08 \mathrm{ha})$, aunque existen otras acumulaciones similares muy próximas y parte del depósito está oculto por la vegetación.

VISTA DEL DEPÓSITO N¹, SITUADO AL PIE DE UN ESCARPE COMPUESTO POR PIZARRAS, CUARCITAS Y ARENISCAS DE LA SERIE DE TRANSICIÓN (A LA DERECHA, NO VISIBLE EN LA IMAGEN). SE PUEDE APRECIAR COMO SE TRATA DE UNA ACUMULACIÓN CLASTO-SOPORTADA, INTEGRADA POR CANTOS Y BLOQUES DE LAS MISMAS LITOLOGÍAS QUE EL ESCARPE. SE ENCUENTRA ESTABILIZADO, COMO INDICA LA DENSA CUBIERTA LIQUÉNICA

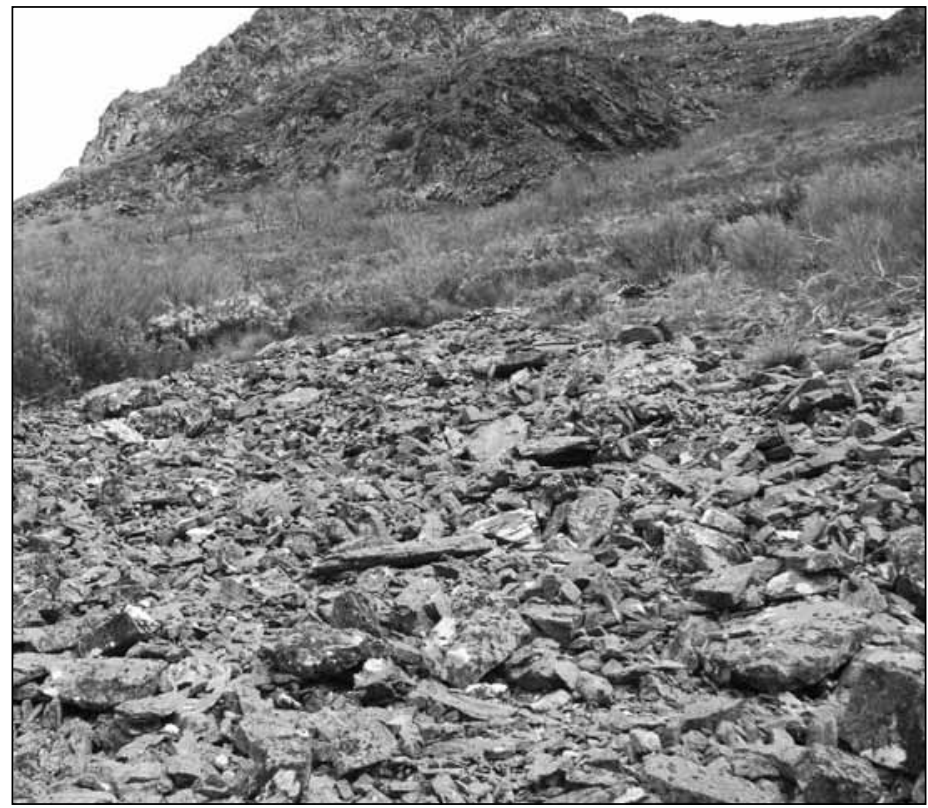


Esta fábrica tan intensa nos indica que se trata de un depósito acumulado por gravedad, en la que los clastos se disponen su eje mayor concordante con la dirección de la ladera en la que se emplazan $\left(\mathrm{N} 290^{\circ} \mathrm{E}\right)$.

Figura 4

REPRESENTACIÓN GRÁFICA DE LA ORIENTACIÓN Y EL BUZAMIENTO DE LOS CLASTOS QUE COMPONEN EL DEPÓSITO N¹. SE PUEDE APRECIAR LA GRAN CONCENTRACIÓN DE LOS CLASTOS EN TORNO AL VECTOR PRINCIPAL $\left(\mathrm{S}_{1}=0,75\right)$, QUE ES COINCIDENTE CON LA PENDIENTE Y ORIENTACIÓN DE LA LADERA SOBRE LA QUE SE ASIENTA EL MISMO

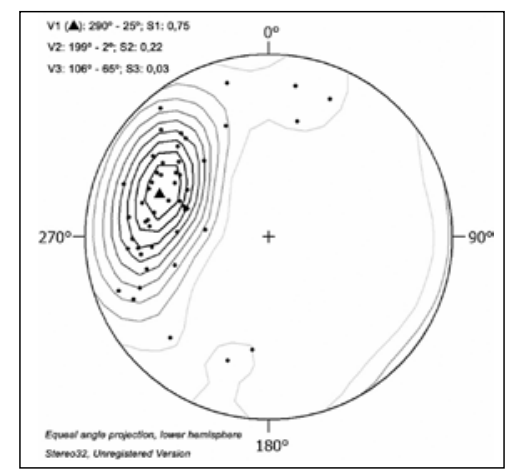

Figura 5

COMPOSICIÓN LITOLÓGICA DEL DEPÓSITO N¹. SE PUEDE OBSERVAR UNA MARCADA DIVERSIDAD LITOLÓGICA, LO QUE EN PRINCIPIO NOS PUEDE LLEVAR A PENSAR EN UN TRANSPORTE DE LOS MATERIALES DESDE DIVERSAS ZONAS. SIN EMBARGO, LOS ESCARPES QUE SE SITÚAN POR ENCIMA DEL DEPÓSITO, PERTENECIENTES A LA SERIE DE TRANSICIÓN, PRESENTAN LA MISMA DIVERSIDAD LITOLÓGICA

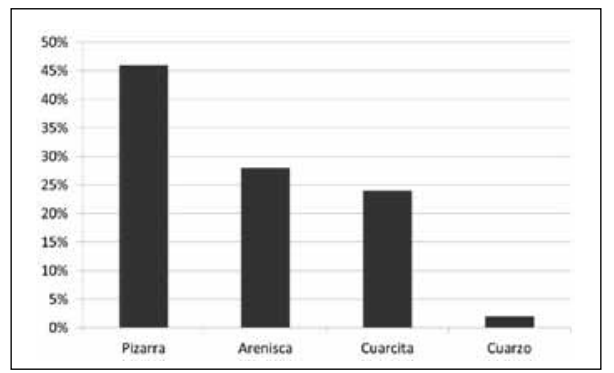

Índice de desgaste: Clase 2 (muy angulosos): $100 \%$

Longitud media: $46 \mathrm{~cm}$. Longitud máxima: $129 \mathrm{~cm}$. Longitud mínima: $24 \mathrm{~cm}$.

\section{V.1.1. Discusión sobre el depósito $n^{0} 1$}

El depósito muestra diversas evidencias de haber sido sedimentado únicamente por la acción gravitatoria, como son: el nulo desgaste de los materiales (todos son muy angulosos), la orientación y el buzamiento de los clastos (que coinciden con las de la ladera) (Figura 4), y la propia 
posición del depósito, al pie de un escarpe rocoso y con una inclinación en torno al ángulo de reposo. La variedad litológica (Figura 5) no entra en conflicto con el resto de los factores, puesto que el probable área de abastecimiento, el escarpe rocoso, está compuesto por los mismos materiales que el depósito: pizarras, areniscas, cuarcitas y algún pequeño dique de cuarzo.

Por tanto, consideramos que se trata de un canchal, acumulado al pie de un escarpe rocoso por gravedad, a partir de la acción combinada de procesos físicos. La densa pátina de líquenes que presenta, así como la cubierta vegetal que recubre la ladera entre el escarpe rocoso y el depósito, indica que actualmente la dinámica que lo generó ha cesado y ya no se producen caídas de material, o estas son muy poco importantes.

\section{V.2. Depósito $n^{0} 2$}

A lo largo de la pista de acceso al Monumento Natural del Lago de la Baña, en la margen izquierda del Valle del Lago, hay varios puntos en los que se observa, en el talud de la pista, la estructura de un depósito matriz-soportado (Figura 6), con matriz de color grisáceo, que integra clastos de litologías variadas (Figura 7) y que tiene una potencia en algunos puntos de, al menos, $3 \mathrm{~m}$. En superficie no es visible, puesto que está colonizado por piornales y robledales, por lo que la estructura interna sólo puede observarse en los cortes antrópicos. Debido a la cubierta vegetal es difícil estimar la superficie que ocupa pues, aunque los restos son numerosos, parece que se emplazan discontinuamente en pequeños hoyos acomodados al abrigo entre los asomos pizarrosos. A $1250 \mathrm{~m}$ de altitud y $50 \mathrm{~m}$ sobre el fondo del valle, realizamos una macrofábrica en un lugar representativo del depósito.

Figura 6

VISTA DEL DEPÓSITO N², MATRIZ-SOPORTADO, INTEGRANDO POR FINOS, ARENAS, CANTOS Y BLOQUES DE LITOLOGIASS DIVERSAS FUERTEMENTE COMPACTADOS POR LA MATRIZ. LA POTENCIA DEL DEPÓSITO ALCANZA EN ALGUNOS PUNTOS LOS 3 M. LA PARTE SUPERIOR APARECE RECUBIERTA POR DERRUBIOS DE PIZARRA

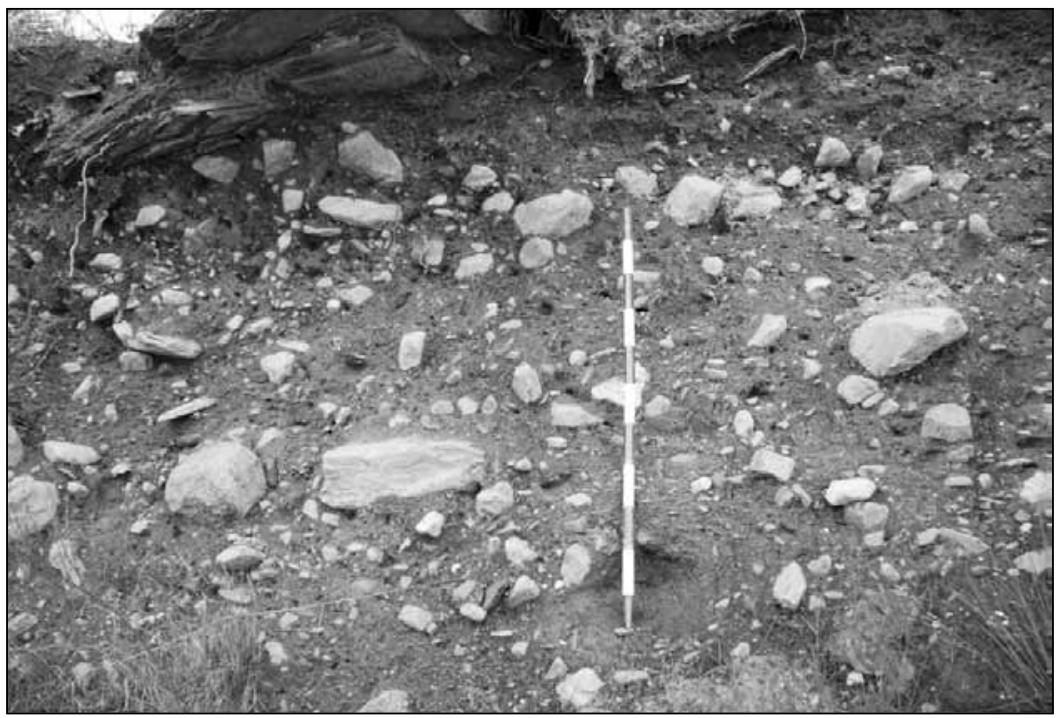


Figura 7

COMPOSICIÓN LITOLÓGICA DEL DEPÓSITO N². A PESAR DE QUE SE ASIENTA SOBRE PIZARRAS, INTEGRA CANTOS DE CUARCITAS Y, EN MENOR MEDIDA, DE ARENISCAS Y PIZARRAS, CON ALGUNOS CUARZOS. LOS AFLORAMIENTOS MÁS PRÓXIMOS DE ESTOS MATERIALES SE SITÚAN UNOS 3 KM AGUAS ARRIBA, EN LAS PROXIMIDADES DEL LAGO DE LABAÑA

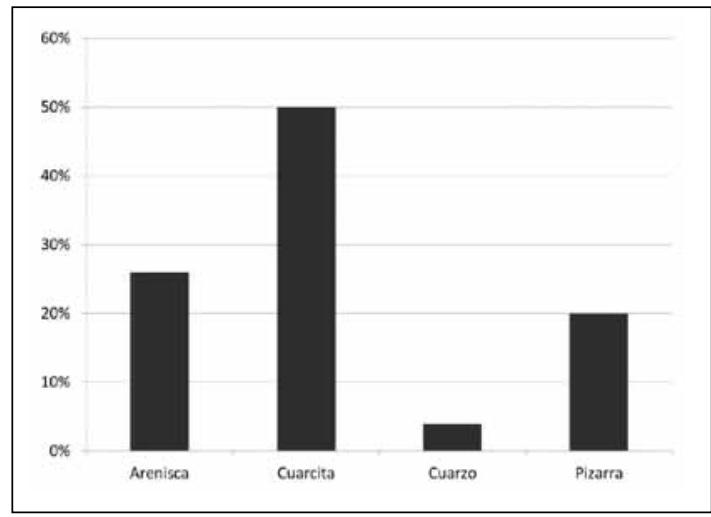

Figura 8

REPRESENTACIÓN DE LA ORIENTACIÓN Y EL BUZAMIENTO DE LOS CLASTOS DEL DEPÓSITO N². SE OBSERVA CIERTO PREDOMINO DE CLASTOS DISPUESTOS HACIA LA CABECERA DEL VALLE, ES DECIR, HAY CIERTA CONCORDANCIA ENTRE LA DIRECCIÓN DEL EJE MAYOR DE LAS PARTÍCULAS Y LA QUE PRESENTA EL VALLE EN ESTE SECTOR. DE TODOS MODOS EL GRADO DE CONCENTRACIÓN NO ES EXCESIVAMENTE ELEVADO $\left(S_{1}: 0,58\right) Y$ NO SON POCOS LOS CLASTOS ORIENTADOS DE FORMA TRANSVERSAL $\left(S_{2}: 0,30\right)$

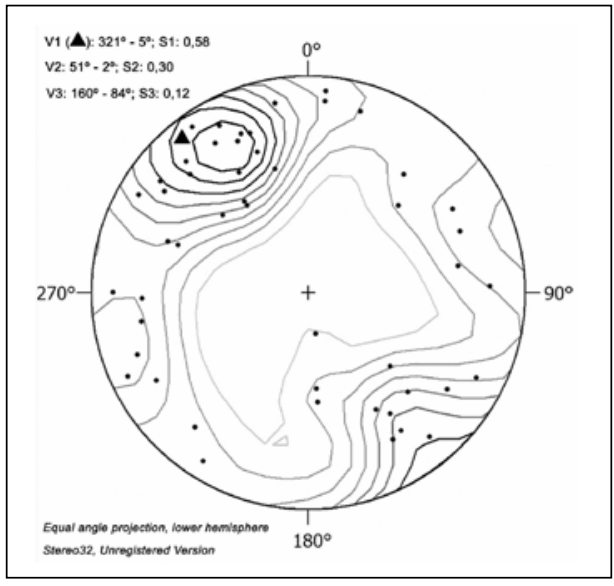

La fábrica muestra que el flujo principal que emplazó el depósito debía proceder de la cabecera del Valle del Lago y no de la ladera, apoyando así el análisis litológico de los materiales que lo componen. 
Índice de desgaste: Clase 2 (angulosos y muy angulosos): $3 \%$. Clase 4 (sub-angulosos): 22\%. Clase 6 (sub-redondeados): $50 \%$. Clase 8 (redondeados): $25 \%$

Longitud media (analizados en la fábrica): $14 \mathrm{~cm}$. Longitud máxima: $39 \mathrm{~cm}$. Longitud mínima: $5 \mathrm{~cm}$.

\section{V.2.1. Discusión sobre el depósito $n^{02} 2$}

Lo más característico del mismo es la matriz arcillosa que envuelve cantos y bloques, así como pequeñas gravas y arenas, existiendo una gran variedad de tamaños. Debido a la fuerte cohesión que ejerce la matriz, la extracción de los clastos es dificultosa. Como hemos indicado anteriormente, el índice de desgaste de los clastos es elevado, predominando los redondeados o sub-redondeados, con aristas romas. Además, litológicamente es variado, incluyendo preferentemente cuarcitas (50\%), areniscas $(26 \%)$ y pizarras $(20 \%)$, con algunos cuarzos (4\%). Esta composición litológica difiere de la del sustrato, que está integrado exclusivamente por pizarras. De hecho, los afloramientos de cuarcitas y areniscas más cercanos están en el Lago de la Baña, a algo más de $3 \mathrm{~km}$ de distancia. En algunas de las areniscas son visibles estrías, aunque no son abundantes. La fábrica realizada indica una orientación preferente NO-SE (Figura 8), si bien su concentración apenas supera el 50\% de la muestra («eigenvalue» $\mathrm{S}_{1}: 0,58$ ). Por otro lado, aunque buena parte de las partículas presentan inclinaciones subhorizontales, existen numerosos cantos subverticales dispuestos transversalmente a la dirección del valle. Estos datos pueden ser indicativos no sólo de las posibles condiciones de sedimentación del deposito (procesos subglaciares de fusión) sino también de los acusados cambios de dirección que presenta el tramo final del valle antes de su confluencia con el río Cabrera.

La variedad litológica del depósito y el hecho de que los materiales no se correspondan con los del sustrato nos indican que ha existido un transporte de los mismos que, dada la localización de los afloramientos próximos, presumiblemente procedan de la cabecera del Valle del Lago. El agente de transporte, dadas las características del depósito, difícilmente puede ser el agua, ya que el mismo está fuertemente cohesionado y no hay ninguna ordenación por tamaños de los materiales. Sin embargo, las observaciones realizadas coinciden plenamente con la adscripción a un origen glaciar, probablemente un till subglaciar de fusión, dada la posición del depósito en la ladera del valle y su buena correlación con formas morrénicas situadas en la otra margen del valle (muy alteradas por las canteras). De hecho, el glaciar que recorrió el valle, dejó acumulaciones de materiales incluso aguas abajo del pueblo de La Baña.

\section{V.3. Depósito $\mathrm{n}^{0} 3$}

En el entorno del Lago de la Baña y de La Laguna un gran depósito de unas 15 ha de superficie es el responsable del cierre del drenaje de ambas masas de agua. En superficie es clasto-soportado y sólo parcialmente está cubierto de matorrales y algunos árboles que han enraizado entre los grandes bloques (Figura 9). No existen cortes que permitan ver su estructura interna. 
Figura 9

ASPECTO GENERAL DEL DEPÓSITO N 3, QUE OBSTRUYE EL AVENAMIENTO DEL VALLE FORMANDO EL LAGO DE LA BAÑA Y DE LA LAGUNA. ESTÁ COMPUESTO POR GRANDES BLOQUES DE PIZARRA SIN SIGNOS EVIDENTES DE TRANSPORTE Y ES CLASTO-SOPORTADO. PRESENTA POCA COLONIZACIÓN VEGETAL, AUNQUE SE INCREMENTA EN LA PARTE MÁS BAJA DEL MISMO. SU LITOLOGÍA ES MUY UNIFORME, COINCIDIENDO CON LAS SERIES PIZARROSAS DE LA LADERAEN LA QUE SE EMPLAZA EL DEPÓSITO

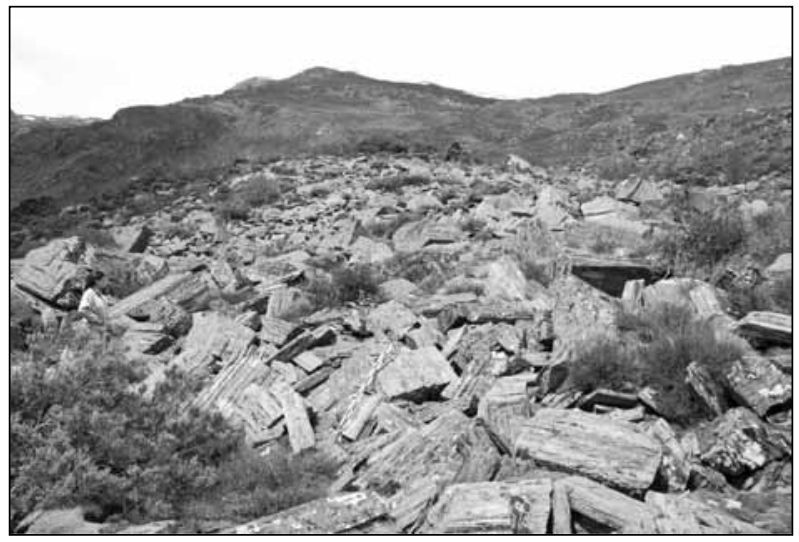

Figura 10

ORIENTACIÓN Y BUZAMIENTO DE LOS CLASTOS EN EL DEPÓSITO Nº 3 (A Y B: MARGEN IZQUIERDA DEL VALLE; C: MARGEN DERECHA DEL VALLE). SE APRECIA COMO PREDOMINAN LIGERAMENTE LOS CLASTOS ORIENTADOS EN EL SENTIDO DE LA LADERA, PERO EL GRADO DE CONCENTRACIÓN ES BAJO (S, EN TORNO A 0,5), Y DISMINUYE HACIA LA PARTE INFERIOR DEL DEPÓSITO. EN REALIDAD, LA FÁBRICA ES POLIMODAL, SIN QUE PERMITA DETERMINAR LA EXISTENCIA DE UN FLUJO PREDOMINANTE, ALGO COMPATIBLE CON QUE SU ORIGEN SEA UN GRAN DESLIZAMIENTO DE ROCAS Y NO UN DEPÓSITO GLACIAR

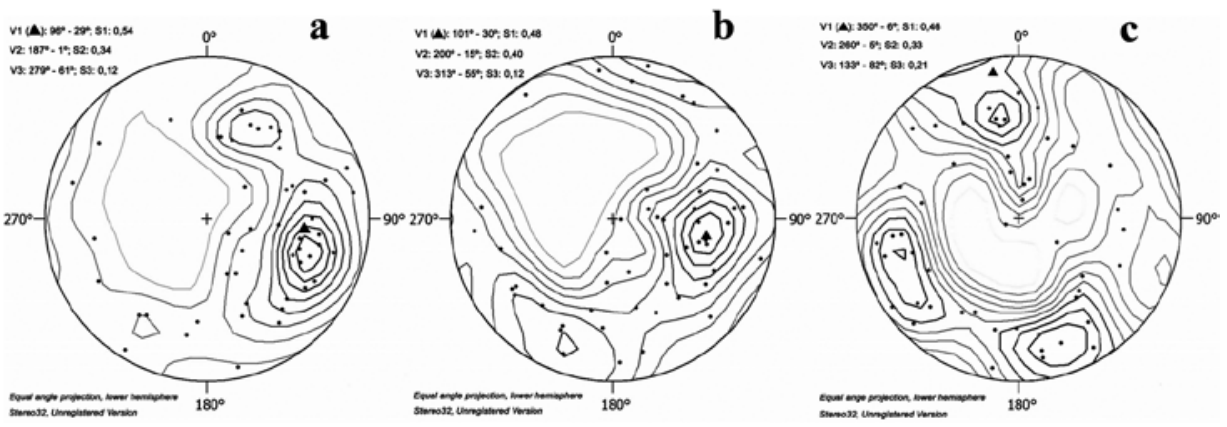

Índice de desgaste: Clase 2 (angulosos y muy angulosos): 100\%

Longitud media: $125 \mathrm{~cm}$. Longitud máxima: $350 \mathrm{~cm}$. Longitud mínima: $60 \mathrm{~cm}$.

\section{V.3.1. Discusión sobre el depósito $n^{0} 3$}

Las tres fábricas realizadas nos muestran que litológicamente es un depósito muy homogéneo, integrado únicamente por pizarras, sin que se hayan observado otros materiales. Estas 
pizarras coinciden con el sustrato subyacente. Por otra parte, el índice de desgaste es muy bajo, siendo todos los clastos observados muy angulosos, con aristas vivas y sin signos de transporte. Las fábricas realizadas muestran que los ejes mayores están mayoritariamente orientados en el sentido de la pendiente de la ladera, si bien el grado de concentración respecto a ese vector principal es más bajo que en el caso del canchal $\left(\mathrm{S}_{1}\right.$ entre 0,45 y 0,54$)$ (Figura 10). De hecho, aparecen clastos en casi todas las posiciones. Las diferencias con el canchal, y con el till, también vienen marcadas por la abundancia de clastos en posición subvertical, siendo mucho más escasos en los citados tipos de depósitos.

Figura 11

VISTA GENERAL DEL DESLIZAMIENTO QUE CIERRA EL LAGO DE LA BAÑA Y DE LA LADERA DE LA QUE, SEGÚN LOS ANÁLISIS SEDIMENTOLÓGICOS, PROCEDÍAN LOS MATERIALES

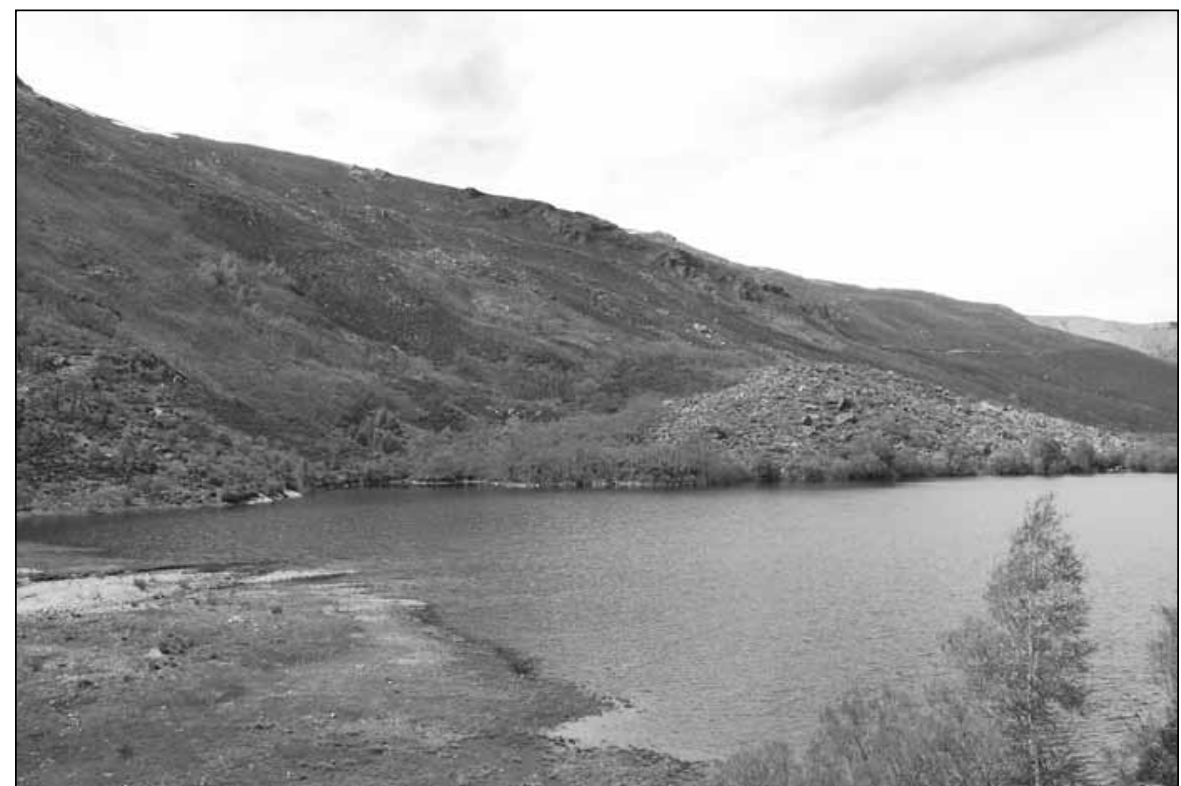

El hecho de que los materiales que lo componen sean exclusivamente grandes bloques de pizarras, de hasta 3-4 metros de eje mayor, idénticas a las del sustrato en ese punto, y que no aparezcan cuarcitas, areniscas o cuarzo, a pesar de la proximidad de los afloramientos aguas arriba, es un indicio que apunta al escaso transporte del depósito, y hace dudar del origen glaciar, incluido un transporte supraglaciar. Similares conclusiones se obtienen al observar la morfología de los clastos, con aristas vivas y sin ninguna evidencia de desgaste. En cuanto a la fábrica, la débil orientación preferente de los ejes mayores no indica un flujo dominante como es propio de agentes sedimentarios como el hielo o el agua, más bien nos lleva a concebir una masa deslizada de la parte alta de la ladera cuyo rápido movimiento obligó a las partículas a colocarse de forma caótica, manteniendo unas veces las misma dirección de la vertiente y colocándose otras perpendicular a la mismas. Las variadas inclinaciones de los clastos, desde valores horizontales hasta buzamientos por 
encima de $80^{\circ}$, hacen pensar también en un movimiento rápido y repentino sin la posibilidad del típico reacomodo que las partículas soportan cuando son movilizadas por flujos más o menos constantes y continuados en el tiempo (glaciar, agua).

Esos bloques de gran tamaño, de haber sido transportados por el glaciar, y dada la friabilidad que caracteriza a las pizarras, se hubieran fragmentado en bloques de menor dimensión. Sin embargo, si el deslizamiento se produjo en un solo evento con muy poca distancia recorrida desde el área fuente, el tamaño y morfometría de las partículas apenas experimentarían cambios desde que se desmembraron del sustrato en la parte alta de la ladera.

Pero es que, además, la morfología del depósito difícilmente es asimilable a la de una morrena, puesto que no se trata de un arco (o varios) bien definidos, sino de una gran acumulación de materiales que tapona la parte baja de una ladera del valle (Figura 11). Por otra parte, la pendiente longitudinal del depósito también lo discrimina de los canchales periglaciares, puesto que existen zonas de poca pendiente, incluso a contra-pendiente, que indican que no se trata de una acumulación procedente de caídas gravitacionales. Además, en la parte alta de la misma ladera se observan abombamientos típicos de las áreas donde se han producido grandes movimientos en masa que contrastan con las áreas adyacentes de las laderas de superficie mucho más regularizadas. Y es precisamente ese origen, el de un gran deslizamiento, el que mejor encaja con todas las observaciones realizadas.

\section{V.4. Comparativa de la forma de las fábricas}

El análisis individual de las macrofábricas refleja diferentes rasgos sedimentológicos para cada depósito. Y esta disimilitud se mantiene en la comparación de la forma que presentan las cinco fábricas, es decir, el modo de distribuirse los distintos valores direccionales, en cuanto a una disposición agrupada ('cluster'), elíptica ('gridle') o aleatoria ('isotrópica'). Los diferentes índices y/o gráficos propuestos (Benn, 1994; Dowdeswell y Sharp, 1986; Woodcok, 1977; Klein, 2002) para determinar la forma de la fábrica a partir de la cuantificación de los principales vectores y valores promedio (análisis de los tensores de orientación o método de 'eigenvalues') reflejan fábricas agrupadas para el canchal y el depósito glaciar, con un índice de isotropía de 0,13 y de 0,40 , respectivamente (Figura 12). En cambio, las tres muestras del deslizamiento plasman fisonomías más planares o aleatorias, con algún caso donde los tres eigenvalues $\left(\mathrm{S}_{1}-0,46-, \mathrm{S}_{2}-0,33-\mathrm{y} \mathrm{S}_{3}-0,21\right)$ tienen concentraciones similares, el índice de isotropía más próximo a $1(0,63)$ y un gradiente $\mathrm{k}(0,88)$ inferior al umbral de 1 .

Los datos comparados de los tres depósitos discriminan de forma clara los análisis realizados en la 'supuesta morrena' que cierra el Lago y de los otros dos depósitos considerados. Las fábricas unimodales donde los cantos tienden a agruparse en determinadas posiciones direccionales son indicativos de la existencia de factores externos que determinan el modo de emplazarse las partículas, ya sea porque existe un flujo más o menos constante que las obliga a ello (lengua glaciar), ya sea porque los rasgos del emplazamiento marcan la posición final del canto (pendiente de la ladera). Por el contrario, las fábricas polimodales y la baja concentración de los valores direccionales en torno al valor propio principal $\left(\mathrm{S}_{1}\right)$ de las muestras del deslizamiento son explicadas mejor por desplazamientos rápidos y súbitos de partículas masivas, los cuales no imprimen unas pautas concretas en el proceso de sedimentación o de emplazamiento final. 


\begin{tabular}{|c|c|c|}
\hline & $\begin{array}{c}\text { Gradiente } \\
K\end{array}$ & $\begin{array}{c}\text { índice } \\
\text { isotropia }\end{array}$ \\
\hline Canchal & 0,47 & 0,13 \\
\hline Depósito glaciar & 0,77 & 0,40 \\
\hline Deslizamiento: & & \\
Muestra 1 & 0,56 & 0,35 \\
Muestra 2 & 0,37 & 0,30 \\
Muestra 3 & 0,88 & 0,63 \\
\hline
\end{tabular}

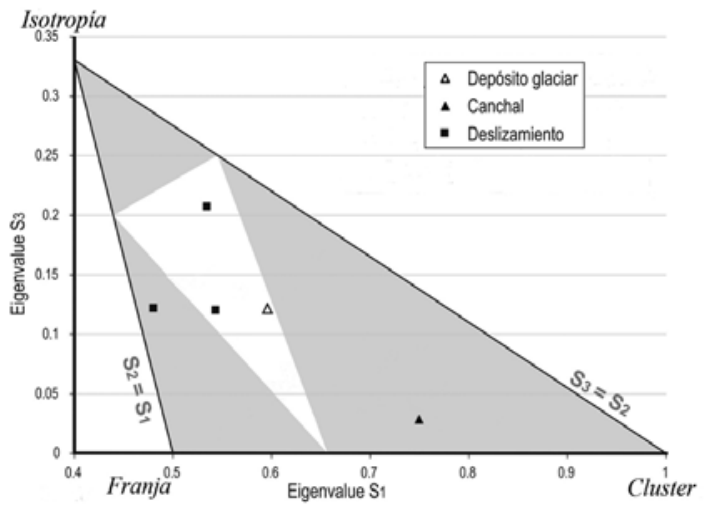

\section{EVOLUCIÓN MORFOGENÉTICA DEL VALLE DEL LAGO}

A partir de las observaciones morfológicas realizadas (Figura 13), apoyadas en los análisis de macro-fábrica de los tres depósitos citados, hemos establecido una cronología relativa de la evolución morfogenética del Valle del Lago:

Máximo glaciar: según las dataciones más recientes en la comarca de Sanabria, el máximo sería al menos anterior al 25.600 A.P. (Rodríguez Rodríguez et al., 2011b). En esta fase todo el Valle del Lago estaría ocupado por un glaciar, con un frente aún no estudiado en detalle. Schmidt (1969) lo sitúa al final del mismo, lo que indicaría un desarrollo de 6,5 $\mathrm{km}$, pero las nuevas observaciones realizadas en las proximidades del pueblo de La Baña, indicarían que el frente pudo situarse incluso por debajo de esa localidad, alcanzando muy probablemente los $10 \mathrm{~km}$ de desarrollo. En todo caso, aún son necesarias nuevas observaciones para concretar en detalle los límites de la glaciación. Durante el máximo se depositarían la mayor parte de las acumulaciones de till, incluido el depósito $\mathrm{n}^{\circ} 2$, así como las morrenas laterales que flanquean el valle, que llegan a situarse (como la morrena lateral derecha a 1553 $\mathrm{m})$ a casi $300 \mathrm{~m}$ sobre el fondo del valle actual.

Etapas de retroceso: apenas se han conservado restos deposicionales que permitan reconstruir las fases de retroceso. Es evidente que en algún momento el glaciar del Valle del Lago se debió individualizar del campo de hielo del Alto Tera, pasando a estar alimentado exclusivamente desde el circo glaciar y quedando acantonado progresivamente en las zonas más elevadas hasta su total desaparición.

Deglaciación: una vez que el valle quedó libre de hielo, los nuevos procesos no glaciares comienzan a operar remodelándolo. Así, los cursos fluviales se encajan progresivamente sobre el fondo de valle. En las laderas, la intensa actividad periglaciar hace que se generen numerosos canchales (depósito $\mathrm{n}^{\circ} 1$ ) que, una vez estabilizados, van cubriéndose de vegetación. Destaca también la formación de algunos conos de derrubios y abanicos aluviales, en ocasiones con formas mixtas como el cono de derrubios que se localiza por encima del Lago de La Baña en la actualidad. 
Figura 13

ESQUEMA GEOMORFOLÓGICO DEL VALLE DEL LAGO
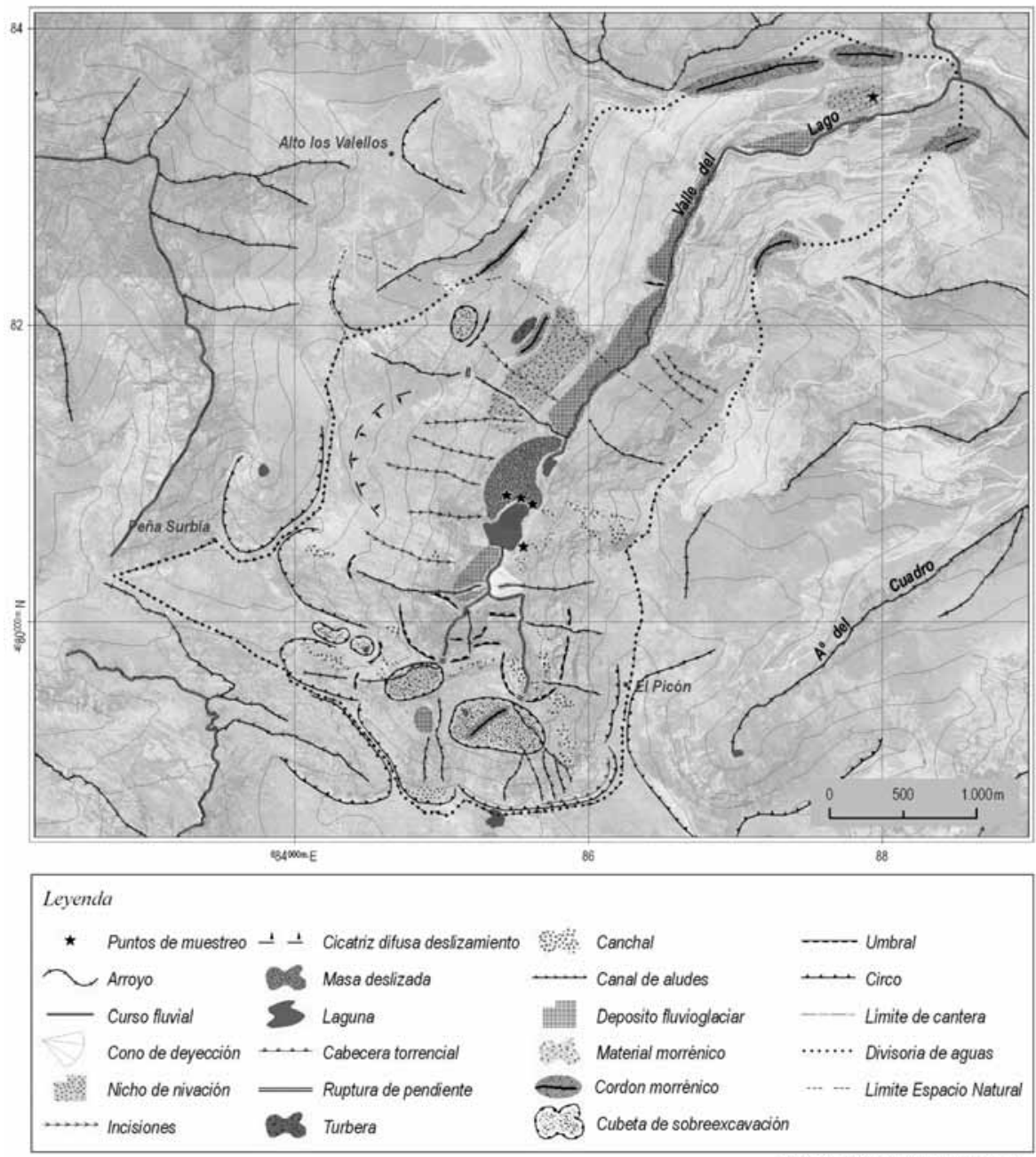

Base cartográfica: http://wwwitacyles

Formación del Lago y la Laguna: Consideramos que la formación de ambas masas de agua, como hemos indicado a partir de la observación en detalle del depósito que los cierra, se debe a un gran deslizamiento de rocas. Este depósito debe ser postglaciar, puesto que no está remodelado por la acción del hielo. Sin embargo, su génesis puede deberse a diversas causas:

- Actividad paraglaciar: los valles recientemente deglaciados sufren un periodo de alta inestabilidad como consecuencia de la descomprensión de las paredes rocosas y la 
gran cantidad de sedimentos poco cohesionados existentes (Ballantyne, 2002). En este contexto, durante la etapa paraglaciar son frecuentes los deslizamientos en masa y, de hecho, muchos de los grandes deslizamientos de la Cordillera Cantábrica que han sido datados se produjeron en esa fase (González-Díez et al., 1996). Asimismo, los de la comarca de Laciana (García de Celis et al., 1992), la cabecera del Carrión (Alonso Herrero, 1994), Somiedo (Menéndez Duarte y Marquínez García, 1996) y la Sierra de Ancares (Pérez Alberti y Valcárcel Díaz, 2001) se consideran probablemente relacionados con la deglaciación. En los Pirineos, se conocen grandes movimientos en masa ligados a la deglaciación sobre sustrato de pizarras paleozoicas en el Alto Gállego (García Ruiz el al., 2004); uno de los escasos ejemplos de lagos no glaciares, el Estany de Llebreta (Lérida), está formado por un deslizamiento de till (Martí i Riba, 1981). En el caso del Valle del Lago, podríamos estar ante un depósito formado poco después de la retirada del glaciar del valle, y ser de tipo paraglaciar, aunque en esta ocasión sin afectar a depósitos glaciares previos.

- Evento sísmico: los terremotos pueden provocar la génesis de grandes deslizamientos en zonas litológica o tectónicamente propicias. De hecho, muchos de los grandes lagos cerrados por deslizamientos en masa se deben a eventos sísmicos, como ocurrió en 1911 con la creación del Lago Sarez, en Tayikistán o en el siglo XVIII cuando se formó el Lago Derborence, en Suiza (Evans et al., 2011). En el NO de España los terremotos no son desconocidos y un evento de cierta intensidad en la zona podría haber causado este deslizamiento. En este caso la edad del lago podría ser más reciente, lo que explicaría su buen estado de conservación a pesar del tipo de depósito que lo cierra.

- Periodo de fuertes precipitaciones: muchos de los grandes deslizamientos en masa están asociados a periodos caracterizados por intensas precipitaciones, que pueden incluir deshielos súbitos, que generan una inestabilidad en las laderas, y el desplazamiento repentino de estas masas de derrubios. En la Sierra de la Cabrera, el paso de los frentes atlánticos deja en ocasiones precipitaciones muy intensas y muy continuadas, que pueden provocar además rápidos deshielos si vienen acompañadas de vientos del SO. En este sentido, un periodo de fuertes precipitaciones singularmente fuerte podría ser el origen del deslizamiento que cierra los lagos.

En cualquier caso, la única datación realizada en el Lago de la Baña (Janssen, 1996), por Carbono 14, se refiere al nivel de $150 \mathrm{~cm}$ de sedimentos de un testigo de $300 \mathrm{~cm}$ (no se especifica si se alcanzó el fondo de los sedimentos) y que arrojó una edad de 1779₫37 años. Por tanto, sin dataciones del fondo del vaso del Lago de la Baña y/o de La Laguna no es posible aún situar en el tiempo la génesis de los mismos, con lo que únicamente se puede afirmar que son post-glaciares.

\section{CONCLUSIONES}

El estudio detallado y la comparación de tres depósitos en el entorno del Lago de la Baña, así como el análisis morfológico de la zona, nos ha llevado a interpretar la acumulación de materiales que cierra estas masas de agua como procedentes de un gran 
deslizamiento en masa post-glaciar, y no una morrena, como la mayoría de los estudios precedentes habían considerado (Carlé, 1949; Schdmit, 1969; Cabero Diéguez, 1980).

En efecto, la elevada homogeneidad litológica, coincidente con la de las laderas próximas, el predomino absoluto de grandes bloques que no muestran evidencias de transporte y la orientación poco definida de los clastos lo diferencian tanto del depósito glaciar como del canchal analizados. Además, la morfología del depósito y de la ladera de donde presuntamente procedía es la característica de los deslizamientos en masa (Mccoll y Davies, 2011). Todos los datos apuntan a un origen no glaciar para estas dos masas de agua, hecho ya apuntado en recientes estudios generales (Alonso Herrero, 2004; Fernández-Martínez, et al., 2009).

Su edad y el factor desencadenante sólo se podrán definir en futuros estudios sobre los sedimentos del fondo del lago, aunque podría estar provocado tanto por la descomprensión de las paredes del valle tras la retirada del glaciar, como por un sismo o por un evento de fuertes precipitaciones.

La constatación del origen no glaciar de estas lagunas de montaña, las hace aún más singulares, puesto que se trata de un origen muy poco frecuente en las montañas ibéricas. Asimismo, su génesis provoca que sean más vulnerables, puesto que la estructura del depósito es poco favorable para la conservación del agua. Así, la mayor parte de los lagos generados por deslizamientos son poco duraderos, debido a la escasa cohesión de los depósitos que los cierran (Evans et al., 2011).

En el caso que nos ocupa, en los últimos años el Lago de la Baña ha sufrido un preocupante descenso en su nivel de agua durante la época estival. De hecho, en el año 2005 el lago quedó prácticamente seco (algo que no había ocurrido con anterioridad) y presentaba sumideros visibles. Por su parte, La Laguna, actualmente sólo es capaz de mantener agua unos meses al año, secándose en verano.

Las continuas voladuras de las canteras de pizarra cercanas, algunas de las cuales se encuentran a sólo $1 \mathrm{~km}$ del lago, son la causa más que probable de la desecación reciente de las lagunas en años muy secos como 2005 (Santos González et al., 2013b). Hay que tener en cuenta que un depósito compuesto por grandes bloques de pizarra, sin apenas finos, es muy vulnerable a las vibraciones producidas por las voladuras próximas. En este sentido, si bien las canteras de pizarra se sitúan fuera del Monumento Natural (aunque llegan al mismo borde), las voladuras asociadas a ellas ponen en peligro la conservación de estas lagunas de enorme valor desde el punto de vista natural y científico, ya que podrían provocar la alteración del depósito de obturación y el completo vaciado de las mismas.

\section{REFERENCIAS}

ALONSO HERRERO, E. (1994): «Geomorfología» en Mapa Geológico de España, 1:50000, $n^{o} 81$, Potes (Rodríguez Fernández, L.R., dir.). Madrid, IGME.

ALONSO HERRERO, E. (2004): «Relieve» en Guía geológica visual de León (Alonso Herrero, E., coord.). León, Celarayn, 160-227.

ALONSO HERRERO, E. y GALLEGO VALCÁRCE, E. (1995): «Puntos de Interés Geológico» en Atlas del Medio Natural de la provincia de León (Gallego Valcárce, E., Alonso Herrero, E., y Penas Merino, A., coords.). Madrid, Instituto Tecnológico Geominero de España, 94-95. 
BALLANTYNE, C.K. (2002): «Paraglacial Geomorphology». Quaternary Science Reviews, $\mathrm{n}^{\mathrm{o}} 21,1935-2017$.

BARETTINO FRAILE, D. (2002): Ordenación minero-ambiental de recursos de rocas industriales. Aplicación a la Reserva Estatal de Pizarras de La Cabrera (León). Tesis Doctoral, Escuela Técnica Superior de Ingenieros de Minas, Universidad Politécnica de Madrid.

BENN, D.I. (1994): «Fabric shape and the interpretation of sedimentary fabric data». Journal of Sedimentary Research, $\mathrm{n}^{\circ} \mathrm{A} 64$ (4), 910-915.

CABERO DIÉGUEZ, V. (1980): Espacio agrario y economía de subsistencia en las montañas galaico-leonesas: La Cabrera. León. Institución Fray Bernardino de Sahagún y CSIC.

CARLÉ, W. (1949): «Testigos de una glaciación diluvial en la Galicia española». Estudios Geográficos, $\mathrm{n}^{\circ}$ 37, 701-706.

DE PRADO, C. (1862): Reseñas geológicas de la provincia de Ávila y de la parte occidental de la de León. Madrid. Comisión Nacional del Mapa Geológico de España. Junta General de Estadística.

DOWDESWELL, J.A y SHARP, M.J. (1986): «Characterization of pebble fabrics in modern terrestrial glacigenic sediments». Sedimentology, $\mathrm{n}^{\mathrm{o}} 33,699-710$.

EVANS, D.J.A. y BENN, B.I. (eds.) (2004): A practical guide to the study of glacial sediments. London. Arnold.

EVANS, S.J., HERMANNS, R.L, STROM, A. y SCARASCIA-MUGNOZZA, G. (eds.) (2011): Natural and artificial rockslide dams. Lecture Notes in Earth Sciences, $\mathrm{n}^{\mathrm{o}} 133$. Springer.

FERNÁNDEZ MARTÍNEZ, E., FUERTES GUTIÉRREZ, I., ALONSO HERRERO, E., REDONDO VEGA, J.M., CORTIZO ÁLVAREZ, J., GÓMEZ VILLAR, A., SANTOS GONZÁLEZ, J., HERRERO HERNÁNDEZ, A. y GONZÁLEZ GUTIÉRREZ, R.B. (2009): Lugares de Interés Geológico. León. DVD. Fundación Patrimonio Natural, Junta de Castilla y León.

GARCÍA DE CELIS, A., GONZÁLEZ FERNÁNDEZ, A., LUENGO UGIDOS, M.A. y REDONDO VEGA, J.M. (1992): «Algunos ejemplos de deslizamientos en el Alto Sil» en Estudios de Geomorfología en España. Actas de la II Reunión Nacional de Geomorfología. (López Bermúdez, F., Conesa García y Romero Díaz, A., eds.). Murcia, 445-453.

GARCÍA FERNÁNDEZ, J. (2006): Geomorfología Estructural. Barcelona. Universidad de Alicante, Ariel Geografía.

GARCÍA RUIZ, J.M., CHUECA, J. y JULIÁN. A. (2004): «Los movimientos en masa del Alto Gállego» en Geografía Física de Aragón. Aspectos generales y temáticos (Peña, J.L., Longares, M.A. y Sánchez, M., eds.). Zaragoza, Universidad de Zaragoza e Institución Fernando el Católico, 141-152.

GONZÁLEZ-DIEZ, A.G., SALAS, L., DE TERÁN, J.R.D. y CENDRERO, A. (1996): «Late Quaternary climate changes and mass movement frequency and magnitude in the Cantabrian region, Spain». Geomorphology, n 15, 291-309.

JANSSEN, C.R. (1996): «Aspects of vegetation development in the Sierra Cabrera Baja. NW-Cantabria. Spain, as part of long-term project in the medium high mountains of 
western and southwestern Europe» en Biogeografía Pleistocena-Holocena de la Península Ibérica (Ramil-Rego, P. Fernández Rodríguez C. y Rodríguez Guitián M., coords.). Santiago de Compostela, Xunta de Galicia, 183-197.

KLEIN, E.C. 2002. Glaciotectonic Shear Zones: Surface Sample Bias and Clast Fabric Interpretation. Tesis doctoral. Universidad de New York. Disponible en: http://pbisotopes.ess.sunysb.edu/reports/

LLOPIS LLADÓ, N. (1957): «Estudio del glaciarismo cuaternario de Sanabria» en El Cuaternario de la Región Cantábrica, V Congreso Internacional del INQUA (Hernández Pacheco, E., Llopis Lladó, N., Jordá Cerdá, F. y Martínez, J.A., eds.). Oviedo, Excma. Diputación Provincial de Asturias, 38-41.

MARTÍ I RIBA, J. (1981): «Estudio del glaciarismo cuaternario en el sector del Alt Ribagorça». Notes de Geografía Física, $\mathrm{n}^{\circ}$ 5, 33-47.

MARTÍNEZ CATALÁN, J.R., GUTIÉRREZ-MARCO, J.C., HACAR, M.P., BARROS LORENZO, J.C., GONZÁLEZ CLAVIJO, E. y GONZÁLEZ LODEIRO, F. (2004): «Secuencia preorogénica del Ordovícico-Devónico» en Geología de España (Vera, J.A., ed.). Madrid, Sociedad Geológica de España e Instituto Geológico Minero de España, 72-75.

MCCOLL, S.T. y DAVIES, T.R. (2011): «Evidence for a rock-avalanche origin for 'The Hillocks' «moraine», Otago, New Zealand». Geomorphology, n 127, 216-224.

MENÉNDEZ DUARTE, R. y MARQUÍNEZ GARCÍA, J. (1996): «Glaciarismo y evolución tardiglaciar de las vertientes en el valle de Somiedo, Cordillera Cantábrica». Cuaternario y Geomorfología, $\mathrm{n}^{\circ}$ 10, 21-31.

MILLAR, S.W.S. y NELSON, F.E. (2003): «Influence of clast axial ratio on macrofabric strength in periglacial colluvium». Journal of Sedimentary Research, $\mathrm{n}^{\circ} 73$ (5), 720-724.

PÉREZ ALBERTI, A. y VALCÁRCEL DÍAZ, M. (2001): «Evolución morfogenética de las vertientes y del fondo de los valles durante el Tardiglaciar y el Postglaciar en el valle de Ancares (Serra dos Ancares, NW peninsular)» en Espacio natural y dinámicas territoriales. Homenaje al Dr. D. Jesús García Fernández (Manero, F., coord.). Salamanca, Universidad de Valladolid, 115-125.

PÉREZ ESTAÚN, A., VELANDO, F., NAVARRO, D., y LÁZARO, J. (1978): «Cartografía», en Mapa Geológico de España. Escala 1:50.000, Hoja 229, La Baña, (Rodríguez Fernández L. R., dir.). Madrid, IGME.

REDONDO VEGA, J.M., GÓMEZ VILLAR, A., GONZÁLEZ GUTIÉRREZ, R.B. y PRIETO SARRO. I. (2004): Patrimonio geomorfológico de los Espacios Naturales Protegidos de la provincia de León. Clasificación, catalogación y cartografía (inédito). Proyecto de Inv. LE64/04, Consejería de Educación, Junta de Castilla y León.

REDONDO VEGA, J.M., GÓMEZ VILLAR, A., GONZÁLEZ GUITÉRREZ, R.B. y SANTOS GONZÁLEZ, J. (2010): Los glaciares rocosos de la Cordillera Cantábrica. León. Universidad de León.

RODRÍGUEZ GUITIÁN, M.A. y VALCÁRCEL DÍAZ, M. (1994): «Contribución al conocimiento del glaciarismo pleistoceno en la vertiente sur-occidental del Macizo de Peña Trevinca (Montañas Galaico-Sanabrienses, NW Ibérico)» en Geomorfología de España (Arnáez Vadillo, J. García Ruiz, J.M. y Gómez Villar, A., eds.). Logroño, S.E.G.

RODRÍGUEZ RODRÍGUEZ, L., DOMÍNGUEZ CUESTA, M.J. y JIMÉNEZ SÁNCHEZ, M. (2011a): «Reconstrucción en 3D del máximo glaciar registrado en la cuenca del Lago 
de Sanabria (Noroeste de España)». Boletín de la Real Sociedad Española de Historia Natural (Sección Geología), no 105 (1-4), 31-44.

RODRÍGUEZ RODRÍGUEZ, L., JIMÉNEZ-SÁNCHEZ, M., DOMÍNGUEZ-CUESTA, M.J., RICO, M.T. y VALERO-GARCÉS, B. (2011b): «Last deglaciation in northwestern Spain: New chronological and geomorphologic evidence from the Sanabria region». Geomorphology, $\mathrm{n}^{\circ} 135$ (1-2), 48-65.

SANTOS GONZÁLEZ, J. (2013): «Análisis de fábrica de depósitos glaciares y periglaciares en el Alto Sil (NO de España)». Comunicación del Conocimiento CCY. Anuario Científico 2012 de la Universidad Isabel I, $\mathrm{n}^{\circ}$ 1, 65-80.

SANTOS-GONZÁLEZ, J., REDONDO-VEGA, J.M., GONZÁLEZ-GUTIÉRREZ, R.B. y GÓMEZ-VILLAR, A. (2013a): «Applying the AABR method to reconstruct equilibriumline altitudes from the last glacial maximum in the Cantabrian Mountains (SW Europe)». Palaeogeography, Palaeoclimatology, Palaeoecology, ${ }^{\circ}$ 387, 185-199.

SANTOS GONZÁLEZ, J., REDONDO VEGA, J.M., GONZÁLEZ GUTIÉRREZ, R.B., GÓMEZ VILLAR, A. y ALONSO HERRERO, E. (2013b): «El deterioro de un Monumento Natural por las explotaciones mineras: el Lago de la Baña, León (España)» en Patrimonio geológico, un recurso para el desarrollo. Cuadernos del Museo Geominero, 15 (Vegas, J., Salazar, A., Díaz-Martínez, E. y Marchán, C., eds.). Madrid, Instituto Geológico y Minero de España, 287-296.

SANTOS-GONZÁLEZ, J., SANTOS, J., GONZÁLEZ-GUTIÉRREZ, R.B., REDONDOVEGA, J.M. y GÓMEZ-VILLAR, A. (2015): «Till fabric and grain size analysis of glacial sequences in the Upper Sil River Basin, Cantabrian Mountains, NW Spain». Physical Geography, $\mathrm{n}^{\circ}$ 36(1): 1-18.

SCHMIDT, H. (1969): «Glazialmorphologische untersuchungen in Bergland. Nordwestspaniens (Galicien-León)». Kölmer Geographische Arbeiten, n 23, 157 pp.

VOSSELER, P. (1931): «Die Ausbildung und Zerstörung tertiärer Rumpfflächen im Nordwesten der Iberischen Halbinsel». Congr. Inter. Geographie. T. II, primer fasc., 536-541.

WOODCOCK, N.H. (1977): «Specification of fabric shapes using an eigenvalue method». Geological Society of American Bulletin, $\mathrm{n}^{\circ}$ 88, 1231-1236. 
